\title{
Amiodarone-induced interstitial pneumonitis
}

\author{
Dinesh Chandra Voruganti, ${ }^{1}$ Linda Cadaret ${ }^{2}$
}

${ }^{1}$ Department of Internal Medicine, University of lowa Hospitals and Clinics, lowa City, lowa, USA

${ }^{2}$ Department of Cardiology, University of lowa Hospitals and Clinics, lowa City, lowa, USA

\section{Correspondence to}

Dr Dinesh Chandra Voruganti, dinesh-voruganti@uiowa.edu

Accepted 6 March 2017
CrossMark

To cite: Voruganti $D C$ Cadaret L. BMJ Case Rep Published online: [please include Day Month Year] doi:10.1136/bcr-2017219373

\section{DESCRIPTION}

A man aged 62 years presented with shortness of breath (SOB) for 1 week. He has a history of nonischaemic cardiomyopathy, diabetes mellitus and atrial fibrillation (AF). ECG revealed AF with rapid ventricular rate and chest X-ray was consistent with pulmonary congestion. He was treated with furosemide and electrically cardioverted for AF. The patient was started on amiodarone $400 \mathrm{mg}$ once daily for maintenance of sinus rhythm. Eight months later, he presented with gradual onset SOB and dry cough. SOB did not improve with diuresis (13 L negative) empiric broad-spectrum antibiotics and mechanical ventilation. Blood cultures for bacteria did not reveal any growth. Urine antigen for legionella was negative, sputum cultures did not show any bacterial growth and PCR testing for Influenza A and B, H1N1, Adenovirus, Respiratory Syncitial Virus, Human Metapneumo Virus, Parainfluenza Virus were negative. The patient underwent flexible bronchoscopy and the mucosa of the visualised airway was normal. Bronchoalveolar lavage (BAL) fluid tested negative for aspergillus galactomannan antigen and histoplasma antigen. BAL cultures for bacteria, acid-fast bacillus and fungus were also negative. CT (figures 1 and 2) revealed bilateral patchy, ground glass airspace disease with honeycombing suggestive of amiodarone-induced interstitial pneumonitis. Pulmonology was consulted and drug-induced lung injury was considered. Amiodarone was discontinued and the patient was treated with oral prednisone $50 \mathrm{mg}$ daily. Over a period of 4 months, he reported significant improvement in his exercise tolerance and SOB. The patient completed pulmonary rehabilitation and he improved from $4 \mathrm{~min}$ of exercise to $22 \mathrm{~min}$. Pulmonary function test in the

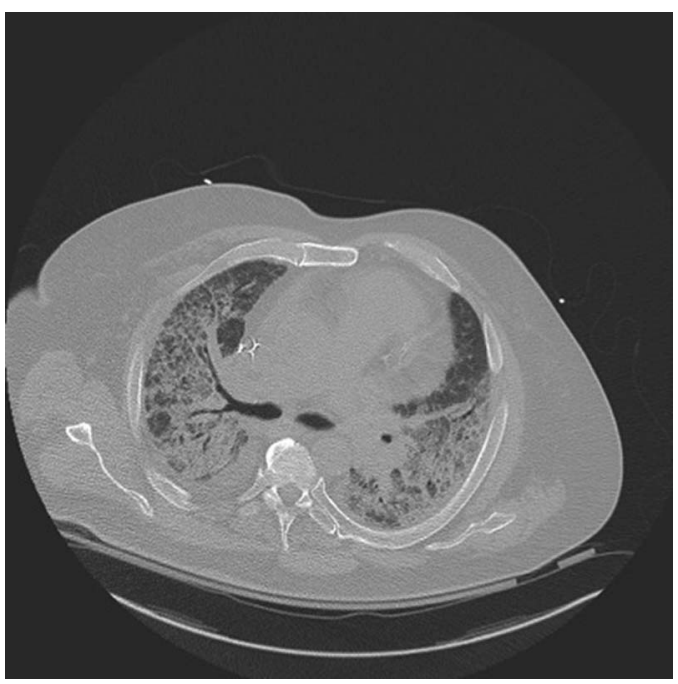

Figure 1 CT-amiodarone-induced interstitial pneumonitis.

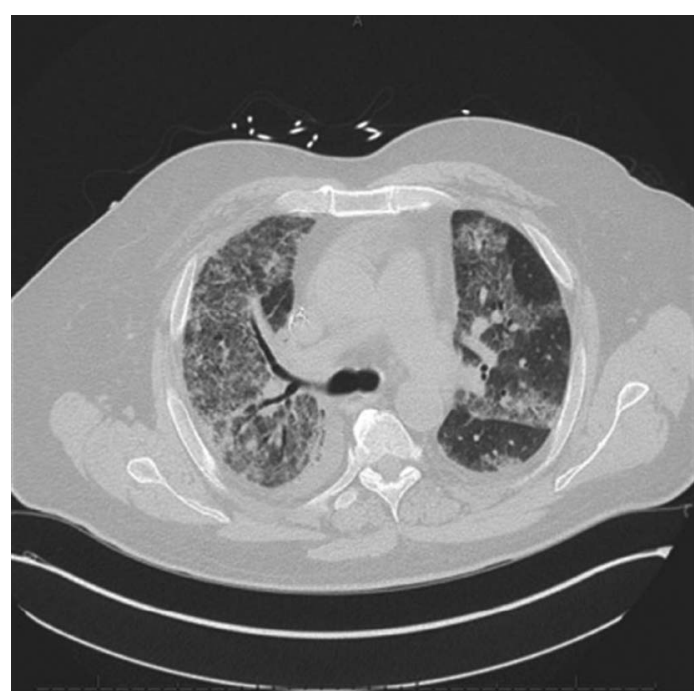

Figure 2 CT-amiodarone-induced interstitial pneumonitis.

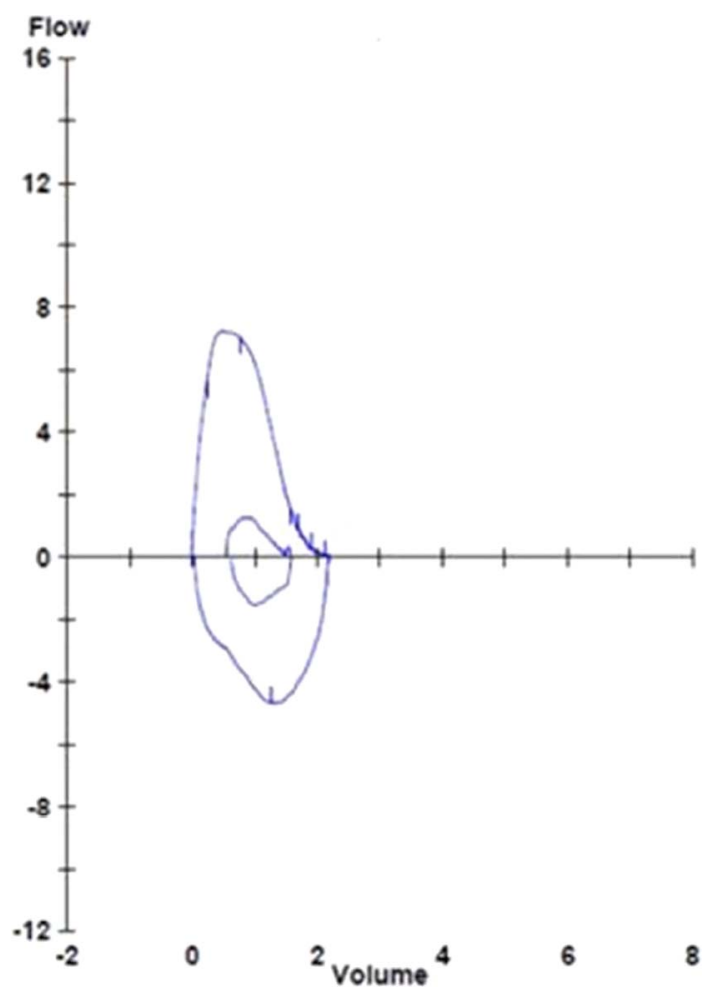

Figure 3 Pulmonary function testing-restrictive pattern.

clinic at 8 months revealed a restrictive pattern and severely reduced diffusion capacity of carbon monoxide (DLCO) (figure 3). CT (figure 4) after 6 months showed significant improvement in airspace disease. Owing to worsening congestive heart failure, the patient received left ventricular assistive 


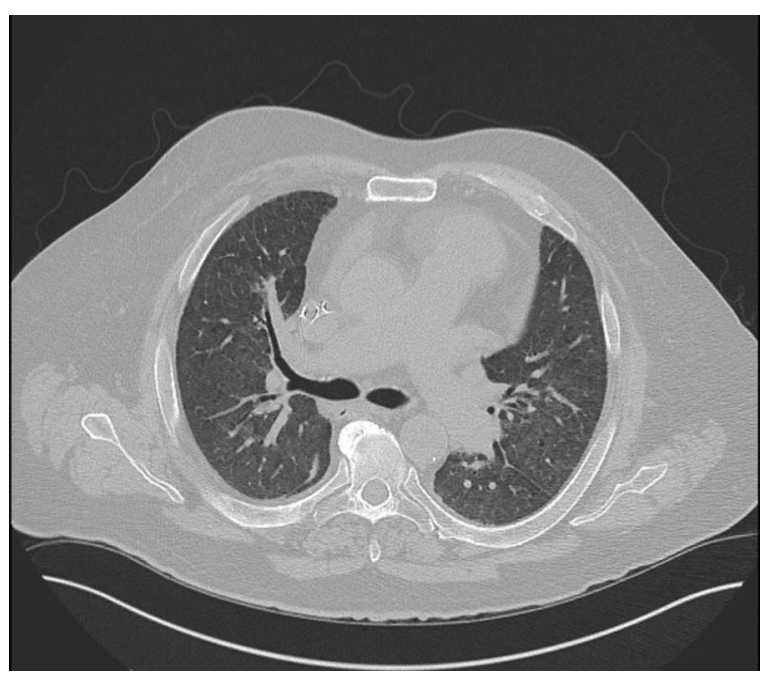

Figure 4 Resolution of interstitial pneumonitis with prednisone treatment after 8 months.

device a year after the diagnosis of amiodarone-induced interstitial pneumonitis.

The differential diagnosis of SOB with bilateral ground glass airspace opacities on CT consists of acute exacerbation of congestive heart failure, interstitial pneumonia and drug-induced pneumonitis. Congestive heart failure may have contributed to the symptoms, but the patient's hypoxia failed to improve after aggressive diuresis. Interstitial pneumonia was less likely as the patient received empiric broad-spectrum antibiotics with no significant improvement and microbiological data were negative. Our patient was diagnosed with drug-induced pneumonitis, caused by amiodarone as a diagnosis of exclusion.

Amiodarone-induced interstitial pneumonitis is characterised by insidious onset of non-productive cough and/or dyspnoea after 6-12 months of amiodarone therapy (dose $\geq 400 \mathrm{mg}$ daily). ${ }^{1} \mathrm{CT}$ of the chest usually shows ground-glass and reticular opacities. ${ }^{2}$ Flexible bronchoscopy with BAL is performed to exclude alternative diagnoses such as infection, haemorrhage or malignancy. A clinical diagnosis of amiodarone-induced interstitial pneumonitis can often be made when the clinical features are consistent and other possibilities like infection and heart failure have been excluded and the patient improves with drug cessation and in some, a trial of glucocorticoid therapy. A lung biopsy is usually deferred unless the diagnosis remains uncertain after cessation of amiodarone therapy and initial therapy with glucocorticoids.

Our patient had a favourable response to cessation of amiodarone and a trial of prednisone therapy with minimal residual lung disease at 8 months follow-up. There was no evidence of infection. Pulmonary function tests revealed a restrictive pattern with reduced DLCO. Therefore, amiodarone-induced interstitial pneumonitis was sought to be the most likely diagnosis. Given his improvement in pulmonary function with prednisone, a lung biopsy was not performed.

\section{Learning points}

- Pulmonary toxicity is among the most serious adverse effects of amiodarone therapy. It is suggested secondary to a direct toxic injury to lung cells and an indirect immunological reaction.

- Clinical diagnosis can often be made when clinical features are consistent and other possibilities have been excluded, patient improves with drug cessation and possibly, a trial of glucocorticoid therapy. ${ }^{3}$ Lung biopsy is usually not necessary if the patients have compatible pulmonary function test and radiographic changes.

- Permanent discontinuation of amiodarone is the primary therapy for amiodarone pulmonary toxicity in addition to systemic glucocorticoids in symptomatic patients. Prognosis is generally favourable. Three-fourths of patients stabilise or improve after withdrawal of the drug with or without glucocorticoid treatment.

Contributors DCV was involved in conception, design and acquisition of data. DCV and LC were involved in drafting and revising the manuscript critically for important intellectual content.

Competing interests None declared.

Patient consent Obtained.

Provenance and peer review Not commissioned; externally peer reviewed.

\section{REFERENCES}

1 Martin WJ, Rosenow EC. Amiodarone pulmonary toxicity. Recognition and pathogenesis (Part I). Chest 1988;93:1067-75.

2 Hudzik B, Polonski L. Amiodarone-induced pulmonary toxicity. CMAJ 2012;184: E819.

3 Wolkove N, Baltzan M. Amiodarone pulmonary toxicity. Can Respir J 2009;16:43-8.

Copyright 2017 BMJ Publishing Group. All rights reserved. For permission to reuse any of this content visit

http://group.bmj.com/group/rights-licensing/permissions.

BMJ Case Report Fellows may re-use this article for personal use and teaching without any further permission.

Become a Fellow of BMJ Case Reports today and you can:

- Submit as many cases as you like

- Enjoy fast sympathetic peer review and rapid publication of accepted articles

- Access all the published articles

- Re-use any of the published material for personal use and teaching without further permission

For information on Institutional Fellowships contact consortiasales@bmjgroup.com

Visit casereports.bmj.com for more articles like this and to become a Fellow 